\title{
The Audit of Business Strategy
}

\author{
Tamás Kozák, Szilvia Szántó \\ University of Applied Businesses, Budapest, Hungary
}

\begin{abstract}
The strategy audit involves evaluation of the actual direction of a business and comparing that act to the direction required to succeed in a changing environment. A company's actual direction is the sum of what it should and should not do, how well the organisation is internally aligned to support the strategy, and how viable the strategy is when compared to external market, competitor and financial realities. These categories, the internal assessment, and the external or environmental assessment, make up the major elements of a strategy audit. In this paper, it presents such a methodology which ensures an integrated process to evaluate the company’s business strategy.
\end{abstract}

Keywords: strategy, risk, analysis, external, internal environment, resources

\section{Introduction}

The continuous adaptation to the competitive market environment and enhancing the ability to compete require a strategic approach in firm governance, even from the directorate of lesser enterprises. According to the classic definition of strategic management, this is "the process of specifying an organization's objectives, developing policies and plans to achieve these objectives, and allocating resources so as to implement the plans. It is the highest level of managerial activity, usually performed by the company's Chief Executive Officer (CEO) and executive team" (Thompson, 2003). Another definition says "Strategic management: strategic analysis, strategic choice, and strategic implementation.” (Johnson, 2006) So, by the quoted definition of strategic management, the focus is on approaching the problems by system thinking, and within this, on developing the organization, the resources, and the corporate culture. Consequently, strategic management is supporting adaptation to the changing environment by realizing conscious change and by concentrating on the fundamental tasks and long-term future of the organization, and it ensures that the everyday activity is goal-oriented, pliable, and conscious.

\section{Methodology}

Strategic approach helps and strengthens foresight and the correlation to the competitors. Approach chiefly means a leading style that "forces" management to ask itself questions about:

- what is the competition about,

- who are the competitors,

- what acquired capabilities, distinguishing resources usable in the competition does the given organization

Tamás Kozák, Ph.D. in Economics, associate professor, Institute of Commerce, Budapest Business School, University of Applied Businesses, Hungary.

Szilvia Szántó, Ph.D. in Economics, associate professor, Institute of Commerce, Budapest Business School, University of Applied Businesses, Hungary.

Correspondence concerning this article should be addressed to Tamás Kozák, Institute of Commerce, Budapest Business School, University of Applied Businesses, Hungary. 
have?

By virtue of understanding the process of strategic management we can formulate the most important requirements of the business strategy. Accordingly, the right strategy defines a behavior, which is a series of actions and activities of the firm, by which_assigning milestones and liabilities—we decide about what exactly to do, based on scaling the goals and expected results. Marking the right goals gives us a guideline at the same time, thereby it serves as a guide to our decisions and helps us to choose between alternative opportunities. All of these require foresight, because we want not just to react on problems with our behavior, but we want to avert, influence, or use them to take shape.

As a special style of handling problems, strategy helps to rank and qualify problems of strategic nature. Right responses given on important/less acute questions make it possible to bring in a verdict that causes a worthwhile change, which makes the long-range goals of the organization reachable and considers the position relative to the competitors. Accordingly, management tasks related to strategic programming and action planning come to the front.

Ranking of problems by strategic consideration, and typical management measures:

\begin{tabular}{|l|l|l|}
\hline $\begin{array}{l}\text { Type of } \\
\text { problem }\end{array}$ & Important & Less important \\
\hline Acute & $\begin{array}{l}\text { CRISIS type of problems requires quick measures of } \\
\text { great consequences. } \\
\text { (e.g. natural disaster) }\end{array}$ & $\begin{array}{l}\text { TACTICAL type of problems requires operative tasks to } \\
\text { be carried out, often based on outer stimulus. (e.g., } \\
\text { supplying of data, making offers) }\end{array}$ \\
\hline Less acute & $\begin{array}{l}\text { STRATEGIC problems require a carefully prepared } \\
\text { system of measures causing significant changes. (e.g., } \\
\text { composing middle-range development plans) }\end{array}$ & $\begin{array}{l}\text { OPERATIVE type of problems requires routine tasks to } \\
\text { be carried out, generally this takes the most time. (e.g., } \\
\text { maintaining relationships) }\end{array}$ \\
\hline
\end{tabular}

As a coordinating activity, strategy makes the recognition and coordination of the expectations of various outer and inner "assigned” groups (stakeholders) possible. The challenges of the outer environment, the intentions of the affiliates of the firm, the expectations of the owners, and the employees draw up different interests, and these can be approached to each other through a strategic plan (Marosan, 2002). As a function of leading, strategy is a basic element of strategic management. It embraces a more complete circle of functions, so partial strategies (e.g., human strategy, financial strategy), corporate culture, strategic goals, and the organization's coordination become parts of the strategic approach and planning, and of the change in management which makes strategic implementation possible.

The strategy determining the long-term operation of the organization is given by matching the strategic system of goals (system of tasks) deduced from the present to the vision of future. The audit of strategy can help in judging how much a business strategy meets the requirements.

The goal of strategy reconsideration is that the leaders get method, instrument, and information for evaluation the business plan and recognizing the advantages and risks offered by current strategies. The strategy reconsideration includes the evaluation of the firm's development goals and the evaluation of the adaptability to the changing environment (Linch, 2006). The effective direction of a firm's development is basically determined by what steps it makes or doesn't make, how much the organization supports strategy, and how much this strategy is competent in view of the intentions of the competitors and the steps already were done. These two categories, the evaluations of inner and outer strategic factors are composing the main elements of strategy reconsideration. The goal of a strategy audit is to get a clear picture about what steps are needed regarding plan correction, or where there is a need for change in the action program and the allocation 
of resources. What are the main steps of strategy audit?

\section{Environment Audit}

In evaluating the outer environment we start from the analysis of the competitors, and the ways in which the firm's (or substitute) products and services are related to the buyers and deliverers (Mintzberg, 2000). The business environment of the organization is never static, and successful firms do not just understand processes taking place in their environment, but they are trying to influence these processes. During a strategic evaluation it is recommended to investigate the following questions in examining the environment of the organization.

In the macro level evaluation of the environment we should measure the basic knowledge, the tendencies, and the problems, which can change significantly, and which are influencing the productivity of the economy's particular branch. Such elements are, for example:

- capital market

- capacity of the particular branch

- technological factors

- new participants' effects on the market

- economic factors

- political factors

- conditioning environment, social customs

- regulations of environmental protection

We can judge how much a firm's strategy considers these macro level factors by direct management interviews or by the analysis of data and information (Moss, 2007). We need answers for such questions as, for example:

- What are the factors that determine the long-term viability of the particular branch?

- Who is the leader of the particular branch?

- What are the macroeconomic factors that determine the productivity of the particular branch?

- What are the critical areas of regulation?

The integration of the results of the environment analysis includes the data processing of stakeholder analysis, competitor analysis, and consumer survey by the means written above, in order to get a whole picture about the characteristics of the particular branch. Integration is made in two steps. The first step is the development of a general picture by primary filtration and summation of the information; then the second is the analysis of the factors significantly influencing the strategical goals and the operational environment. The former step is made basically by a qualitative processing of information; and the latter means basically quantitative methods and financial modeling in order to evaluate what effect the changes of chosen macroeconomic indicators' values have on the profitability of the firm's activity, and on the business value of the firm. The examination of the outer factors - the influencing ability of which presumes a mapping of the firm's resources - and the adaptation to the environment leads us to the evaluation of the firm's competences.

In the analysis of the competitors' strategy we are looking for answers about, for example, what are the main elements of the competition, "in what are they better than us", what are the characteristics of the "champions" of the particular branch? What are the "entrance barriers" that new participants have to take into 
account, and what effect have these on our own market share?

\section{Resource and Competency Audit}

The starting point for this part of the strategy audit is the understanding of the dynamics and inner components of the particular branch. The spine of the investigation is the relationships between competitors, buyers, and interested participants (stakeholders), and these contain the following dimensions.

During the examination of the financial questions we should evaluate, for example, the need of funds and the characteristic operational cycle of funds. We get a picture about the typical/acceptable level of indebtedness and the special conditions (e.g., cover) of getting resources in the particular branch. In a benchmark analysis we can get a picture about what is the typical construction of resources and funds of the leaders of the particular branch, and what instrumental efficiency are they operating with.

In mapping the characteristics of the organization, we search answers for such questions as, for example, what is the typical operation model of a corporation group like? Are the characteristic decision processes centralized or decentralized? How is ownership control realized? Examining human resources includes efficiency analysis and the measuring of knowledge bases. It's important for the leading participants of the particular branch to get to know the fundamental elements of these.

\section{Evaluation of the Strategic Plan}

After the environment examination of the firm, there comes the audit of the enterprise itself, regarding how much the inner competences and resources serve the realization of strategic goals. In the same time this stage means a feedback about the quality of the strategic plan, because by criteria analysis we can get an idea about having the required inner resources and competences, and about what increase in value and efficiency comes from the realization of the program plans. One of the most widespread, intuitive, and heuristic methods for examining strengths and weaknesses is the SWOT analysis, and it is important that the action plan defined by this should be in accordance with the primer evaluation (the SWOT analysis).

Main steps of the competence evaluation of the firm:

Evaluating the intelligibility of the strategy sheds a light on how clear the vision of the firm's future is? What the most important strategic goals are? And what the basic criteria of success are? If any of these is not clear enough, it's impossible to compose a team fully committed to the firm in favor of success.

During manageability examination we can get a picture about what factors can hamper the realization of the strategic plan. By risk analysis we can filter out those market and financial factors that may endanger the realization of the goals, and we can also check it out that how ready the management is to prevent or handle the consequences of unexpected events and damages.

The examination of the business processes shows that in what degree each element of the value chain contributes to the firm's added value, how efficient the use of resources is, and where reorganization is needed to make processes serve the realization of the strategic goals better.

The weighing of the abilities means the accounting of such value increasing knowledge base and special knowledge that add to the business value as strategic resources. The survey has two parts: which abilities serve the execution of the strategic plan, and which competences are required to maintain a market position. To manage the change successfully, we need to know what capabilities we can depend upon, and where further 
development is needed.

Reconstructing the organization and allocating the resources are parts of the change management process. Changes, namely the coordination of processes, organization and resources have to increase the efficacy significantly, otherwise strategy remains only a collection of wishes.

Measuring corporate culture includes the knowing of the fundamental values, the evaluation of the style of leading, and the review of those prejudices and beliefs, which may hamper or help waking the strategy.

\section{Conclusions}

There are four questions we need to give a definite answer for. They are these:

(1) Does our strategy fit to the environmental changes and requirements?

(2) Are our resources, abilities, and improvement opportunities in accordance with our goals?

(3) Based on the answers to the questions above, which are the most important indexes marking the achievement of our strategic goals, and how these indexes change, and is this change acceptable by the owners?

(4) Is the management able to start and lead changes, and is the whole company ready for the change?

As a matter of fact, with the answer for the first three questions we audit the process of strategic planning, and the result of this process. We should get a picture about how much the management payed respect for the social expectations, threats, and opportunities of the environment as well as the expectations of the owners. These also show us how efficiently the management leaded the organization through the tasks of strategic planning.

The mission, which defines the place of the firm in the society, and the vision of future based on the mission, which contains the system of developmental goals for long-term subsistence, should give a clear and clean-cut guidance for everyone in the enterprise.

In the next step, the current (environment, resource, organization, and operation process) status characteristics of the firm can be defined to uncover the strengths and weaknesses of these. The main question is how much are the strategic tasks — defined for development toward strengths and for fencing off weaknesses (dangers) —in accordance with the environmental and corporate preferences and capabilities.

Partial strategies meant for realizing strategic goals should be in accordance with the system of strategic goals and with each other. By using strategy and the system of strategic goals (partial strategies) management composes the middle-term strategic plan of the organization. It is important that the action plan serving the realization of goals helps to manage and control the changes by appointing tasks, liabilities, and deadlines (Nabradi \& Pupos, 2010).

Changing and making changes mean completing the tasks appointed by the strategy, that is to say, making the strategy come to life. And this can be the way for the realization of some overall goals. Changes in the organization go hand in hand with, for example, the reallocation of resources, the conquest of new markets/buyers, the development of efficiency. Typically, leaders should make changes have effects on the whole organization to reach a higher stage of corporate life cycle. Generally, there is a strong opposition against changes. Employees are afraid of the unknown. Many of them have doubts that completing organizational changes can be really effective, and goals opposing these changes often evolve inside the firm. The answer to the fourth question evaluates the ability to break through these barriers. We can say: a strategy is worth to realize only if we get satisfying answers to the questions related to the audit. 


\section{References}

Linch, R. (2006). Corporate strategy, 48-41. Harlow, England: Pearson Education.

Johnson, G. et al. (2006). Exploring corporate strategy, 52-54. Harlow, England: Pearson Education.

Marosán, G. Y. (2002). Stratégiai menedzsment, 56-60. Budapest: Calibrai Könyvkiadó.

Mintzberg, H. (2000). Planning on the left side and managing on the right, 58-71. London: HENRY J. Sage.

Moss, D. A. (2007). A concise guide to macroeconomics: What managers, executives, and students need to know, 10-12. Boston,

MA: Harvard Business School Press.

Nábrádi, A., \& Pupos, T. (2010). A stratégiai és üzleti tervezés gyakorlata, 24-57. Budapest: Szaktudás.

Thompson, A. A. et al. (2003). Strategic management: Concepts and cases, 39-40. McGraw-Hill/Irwin. 